\title{
Cross-Case Analysis: K-12 International Teachers' Perspectives on Integrated STEM and Computational Thinking Practices
}

\section{Mrs. Cristina Diordieva, Texas Tech University}

Mrs. Cristina Diordieva is the Project Coordinator for the World MOON Project. Mrs. Diordieva is currently a doctoral candidate in Educational and Instructional Technology (EDIT) program and minoring in Bilingual Education in the College of Education at Texas Tech University. She earned a BA majoring in French and minoring in Linguistics from Texas Tech University. She is highly interested in conducting research within the multidisciplinary studies that encompasses second language acquisition in educational technology and online learning as well as designing engineering online courses. In addition, in 2017, she became the first and only individual to obtain the Diplôme de Français Professionnel from the Chamber of Commerce of Paris Professional French at Texas Tech University. Also, she received the 2017 Paul Whitfield Horn Fellowship Award and Helen DeVitt Jones at Texas Tech University. Mrs. Diordieva looks forward to expanding her research and teaching practices in a higher education research institutions and can be reached at cristina.diordieva@ttu.edu.

\section{Dr. Ibrahim H. Yeter, Purdue University-Main Campus, West Lafayette (College of Engineering)}

Ibrahim H. Yeter is currently a Postdoctoral Researcher in the INSPIRE Research Center in the School of Engineering Education at Purdue University. He obtained his PhD in Curriculum and Instruction emphasizing in Engineering Education and Master's degree in Petroleum Engineering at Texas Tech University. $\mathrm{He}$ is highly interested in conducting research within the Engineering Education framework.

Recently, he received the Early Career Researcher Award from European Science Education Research Association (ESERA) in 2017. In addition, he is one of two scholarship recipients awarded by National Association for Research in Science Teaching (NARST) to attend the ESERA summer research conference in České Budějovice, Czech Republic in August 2016. He has also been named as Jhumki Basu Scholar by the NARST in 2014.

Additional projects involvement include: PictureSTEM, STEM+C, Engineering is Elementary (EiE); Rocket Project; World MOON Project; and Robotics. He can be reached at iyeter@purdue.edu.

\section{Dr. Walter Smith, Texas Tech University}

Helen DeVitt Jones Professor of Education 


\section{A Cross-Case Analysis: K-12 International Teachers' Perspectives on Integrated STEM and Computational Thinking Practices}

Mrs. Cristina Diordieva, College of Education, Texas Tech University

Dr. Ibrahim H. Yeter, School of Engineering Education, Purdue University

TEXAS TECH UNIVERSITY

College of Education

\section{Abstract}

The purpose of this study is to conduct a cross-case analysis method to investigate K-12 international teachers' views on integrated STEM and computational thinking practices via World MOON Project. The World MOON Project is an international STEM (i-STEM) collaborative project that thousands of international K-12 students and hundreds of teachers have been exposed to, as well as various res world, such as, from Australia, Brazil, China, South Africa, and the United States. In this project, students conveyed their observed patterns in an essay format and exchange with their peers. This allows students to investigate how their observed patterns result are the same or different. More importantly, this project carries an important role for international collaboration in aerospace and STEM education by relating to the specific curricular goals, such as, including aerospace, inquiry skills, nature of STEM.
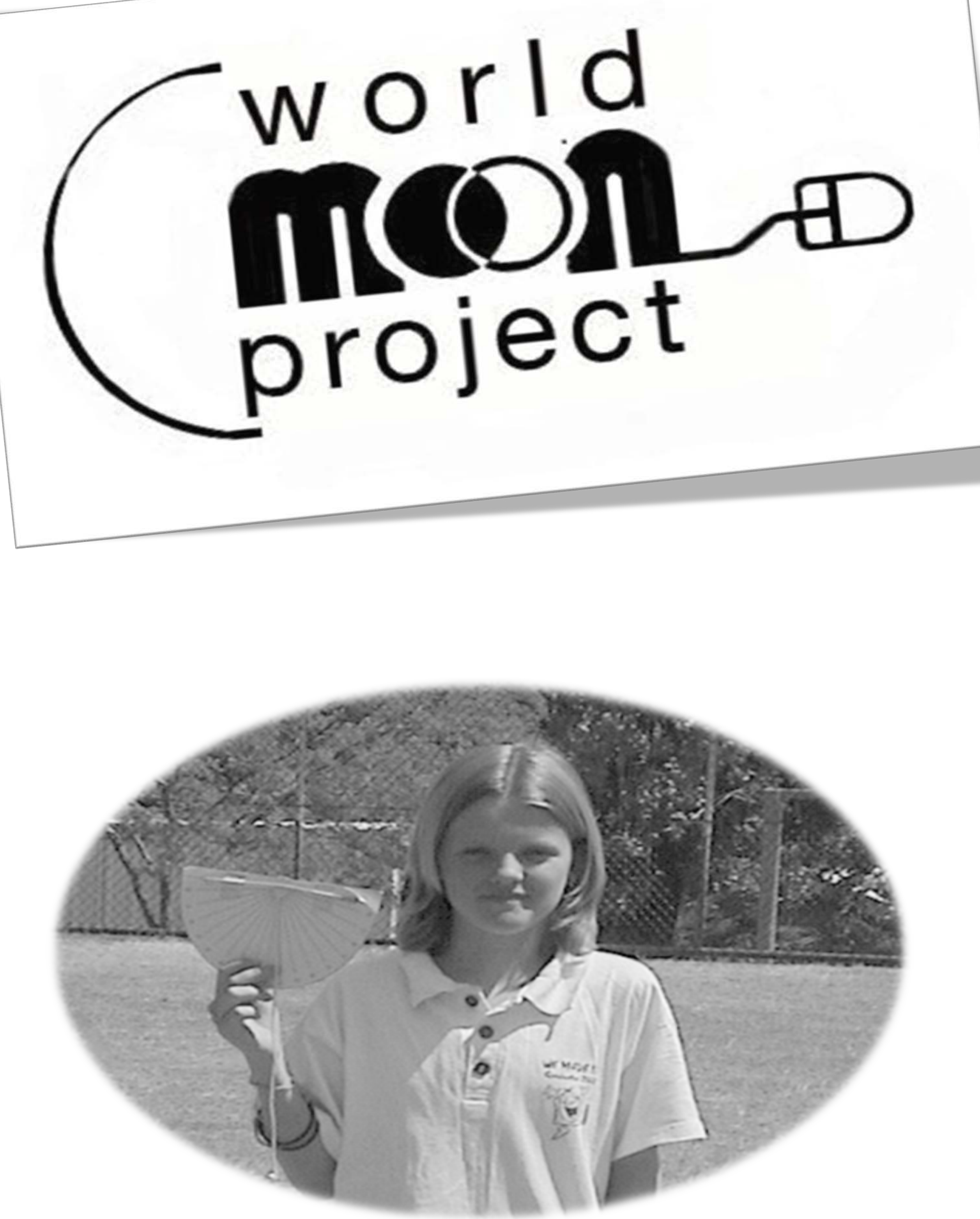

Introduction

The project is established to provide inquiryand project-based learning in science, technology, engineering and mathematics (STEM) disciplines as well as computational thinking (CT) practices such as observing and identifying patterns in aerospace objects (e.g., moon phases). Integrated STEM and CT practices are implemented heavily in the project to make the learning environments more meaningful to the students while they collaborate with their peers from different countries.

\section{Method}

The qualitative research methodology (i.e., cross-case analysis) will be used to determine all the participated teachers' views on integrated STEM and CT as well as their needs and outcomes for this global project. For 2017-2018 school year, there are 32 teachers participated in this project and 17 of them accepted to be in this specific study. The anticipated data from the 17 teachers will be collected from two different sources, such as, semi-structured interview and document artifacts. The semi-structured interviews with the teachers, as well as followup emails, will be conducted to look in-depth about their views.

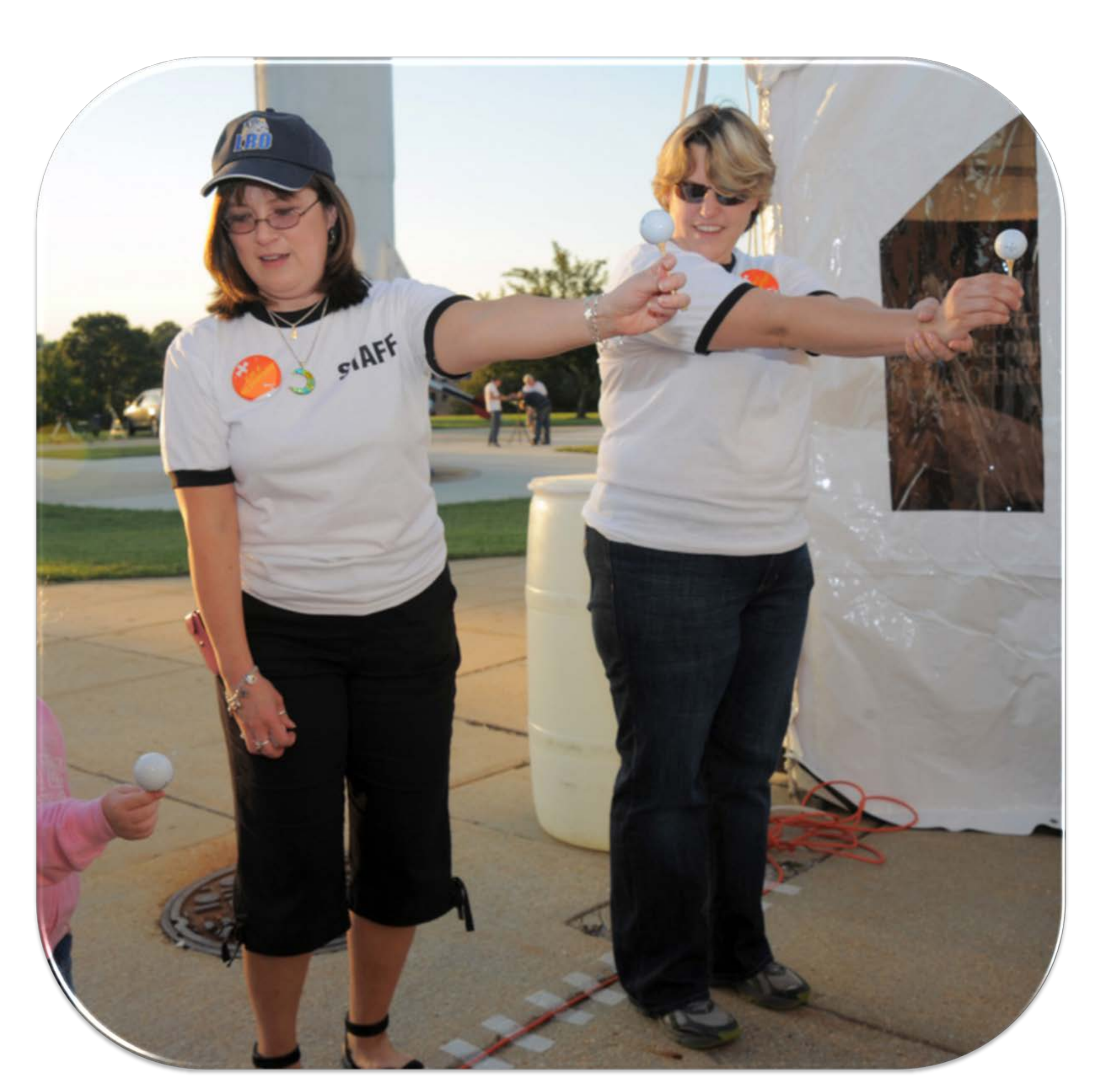

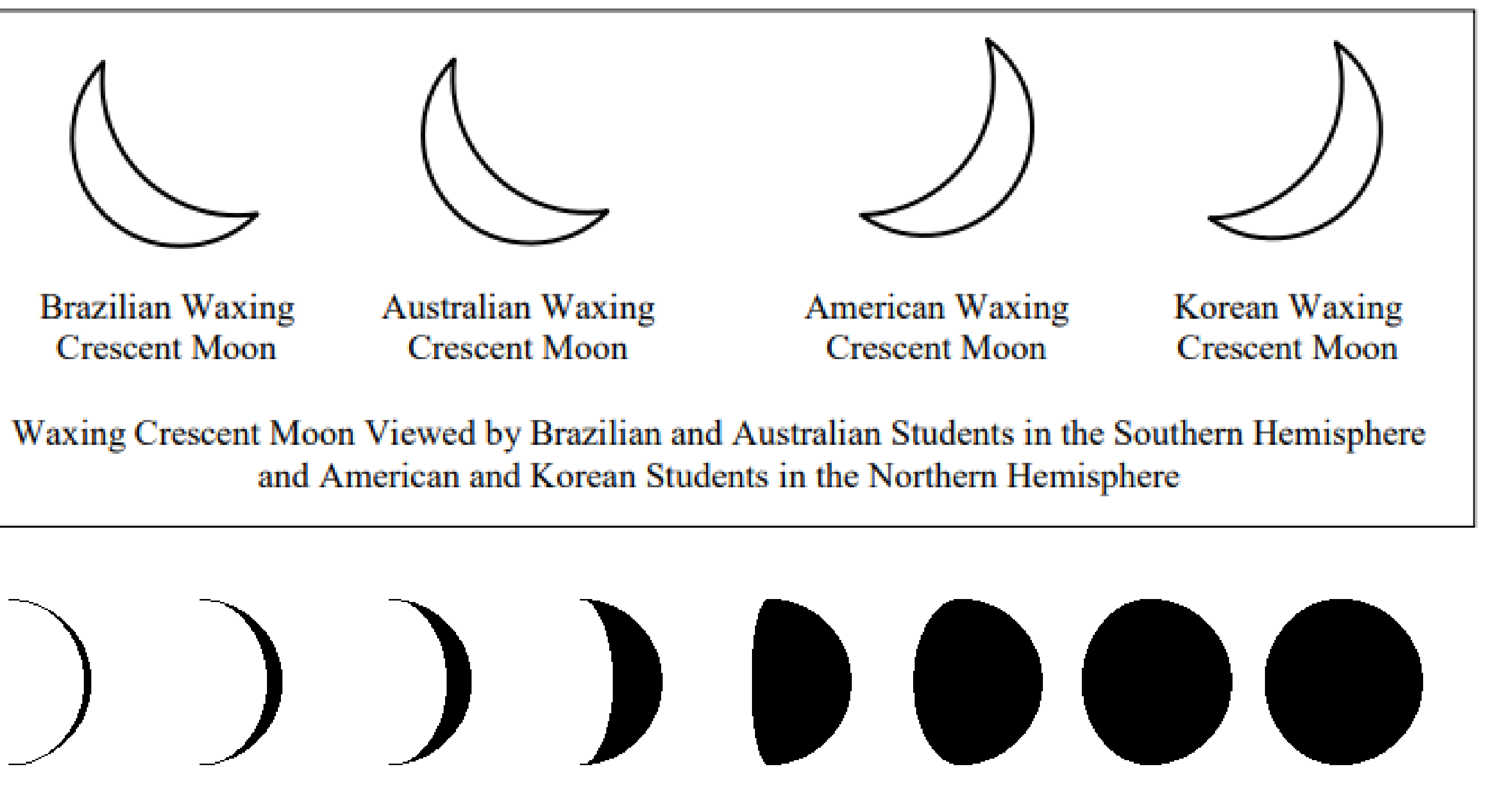

$\underline{\text { Result }}$

The anticipated results indicate that this project helped students to improve throughout the semester their:
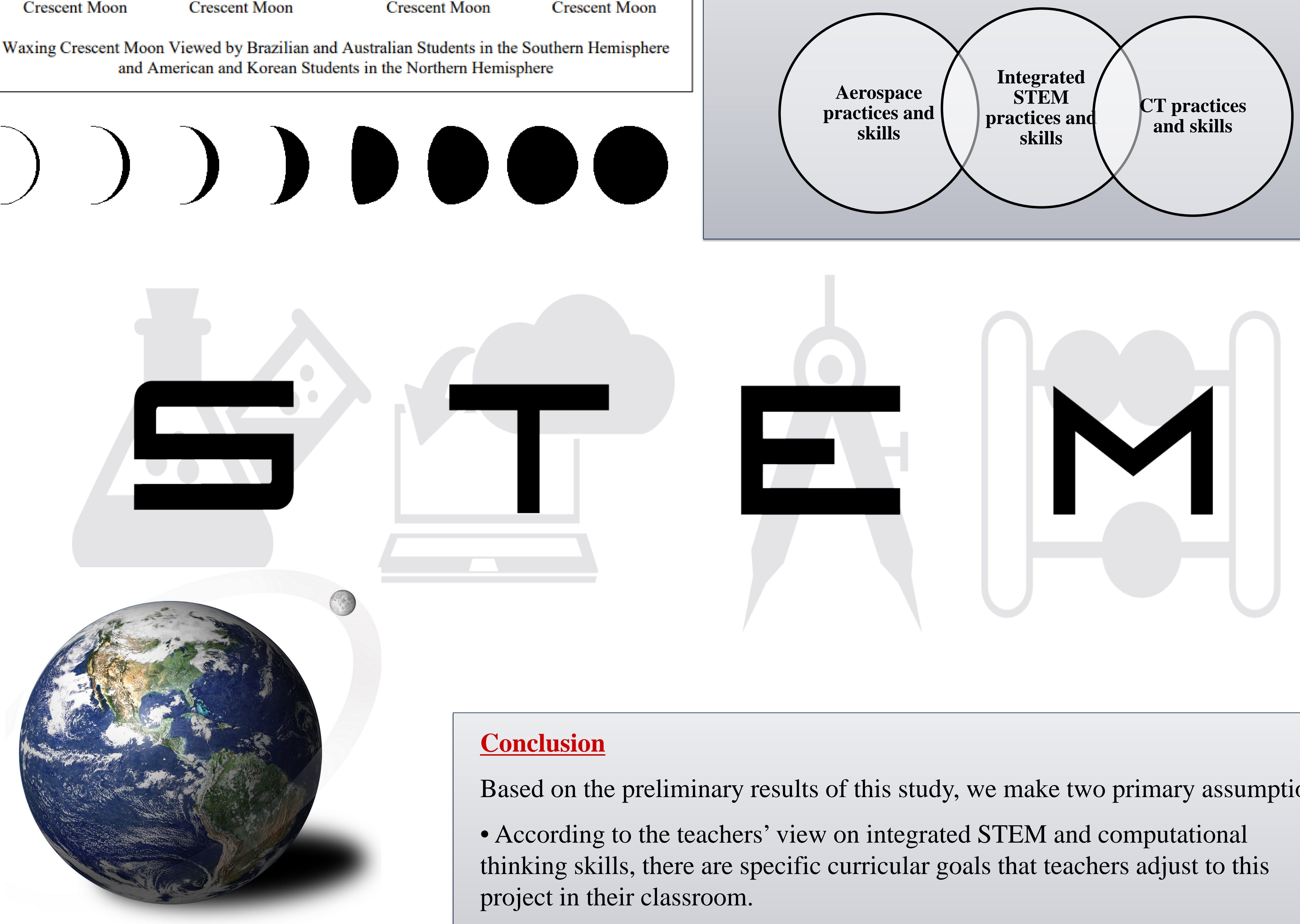

Conclusion

Based on the preliminary results of this study, we make two primary assumptions:

- According to the teachers' view on integrated STEM and computational thinking skills, there are specific curricular goals that teachers adjust to this project in their classroom.

-According to the teachers, this global project improved students' knowledge in

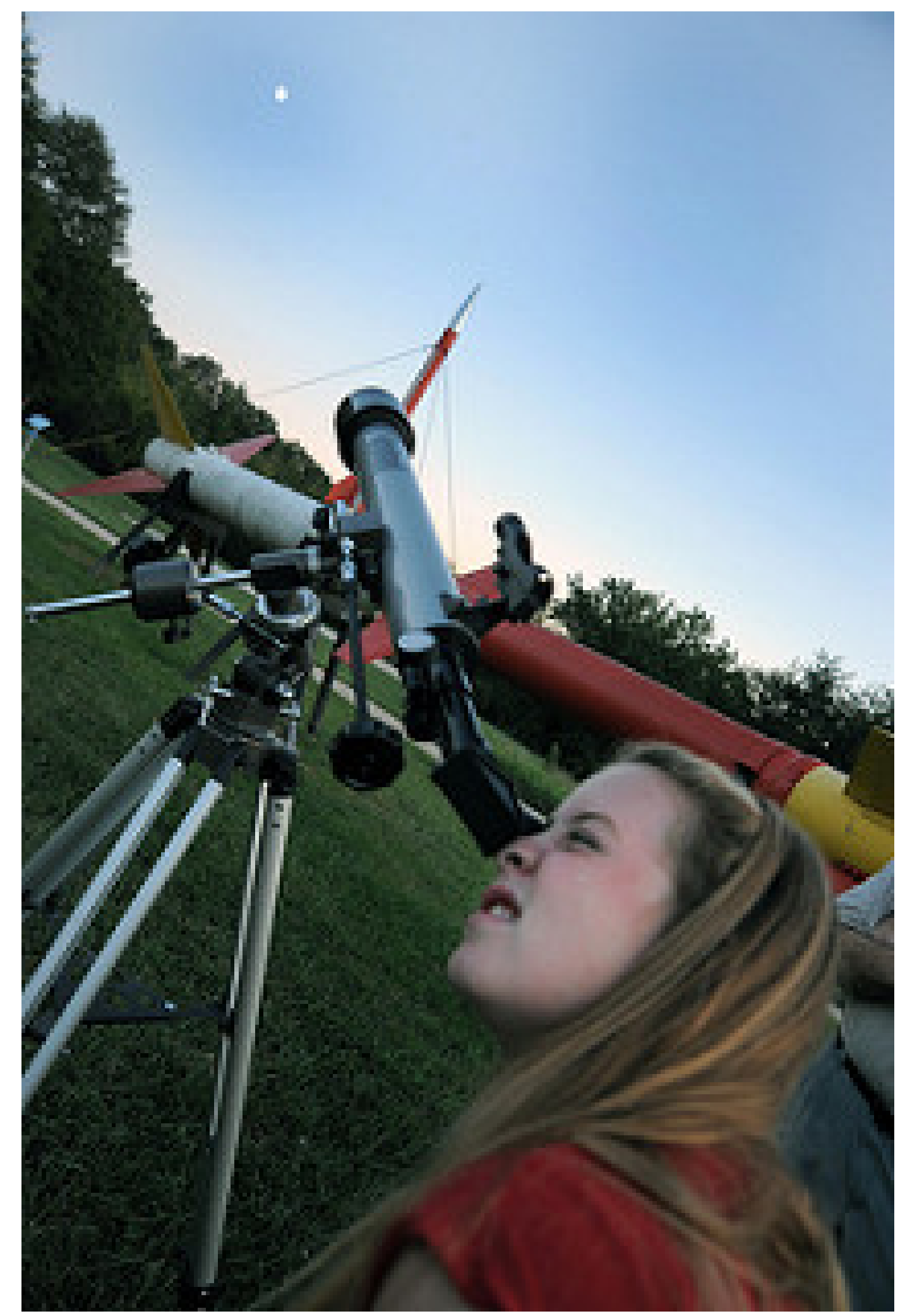
science topics as well as acquiring CT skills in the classroom.
Contact Information

Mrs. Cristina Diordieva is the Project Coordinator for the World MOON Project. Cristina Diordieva is currently a doctoral candidate in Educational and Instructional Technology (EDIT) program and minoring in Bilingual Education in the College of Education at Texas Tech University. She earned a BA in French and minoring in Linguistics. Mrs. Diordieva looks forward to expanding her research and teaching practices in a higher research institutions and can be reached at cristina.diordieva@ttu.edu. 